\title{
Upper Bound Solution of Safety Factor for Shallow Tunnels Face Using a Nonlinear Failure Criterion and Shear Strength Reduction Technique
}

\author{
Fu Huang, Zai-lan Li, and Tong-hua Ling \\ School of Civil Engineering and Architecture, Changsha University of Science and Technology, Changsha, Hunan 410114, China \\ Correspondence should be addressed to Fu Huang; hfcsu0001@163.com
}

Received 5 February 2016; Accepted 26 April 2016

Academic Editor: Yakov Strelniker

Copyright @ 2016 Fu Huang et al. This is an open access article distributed under the Creative Commons Attribution License, which permits unrestricted use, distribution, and reproduction in any medium, provided the original work is properly cited.

A method to evaluate the stability of tunnel face is proposed in the framework of upper bound theorem. The safety factor which is widely applied in slope stability analysis is introduced to estimate the stability of tunnel face using the upper bound theorem of limit analysis in conjunction with a strength reduction technique. Considering almost all geomaterials following a nonlinear failure criterion, a generalized tangential technique is used to calculate the external work and internal energy dissipation in the kinematically admissible velocity field. The upper bound solution of safety factor is obtained by optimization calculation. To evaluate the validity of the method proposed in this paper, the safety factor is compared with those calculated by limit equilibrium method. The comparison shows the solutions derived from these two methods match each other well, which shows the method proposed in this paper can be considered as effective.

\section{Introduction}

Shallow tunnels are very common nowadays in municipal engineering construction as they make traveling more convenient and also reduce engineering costs. Though shallow tunnels have a number of advantages, accidents due to instability of tunnels face would occur if the supporting pressure cannot resist the earth pressure. Thus, to avoid the occurrence of such accidents, it is necessary to determine the suitable retaining pressure on the tunnel face. The stability analysis of the face for a tunnel excavated in shallow strata has drawn the attention of many investigators [1-4]. On the other hand, the retaining pressure on the tunnel face is constant in practical engineering when the earth pressure balance of tunnel face is achieved by using compressed air or bentonite slurry. Therefore, it is necessary to establish a method to evaluate the stability of tunnel face when the retaining pressure is known. The safety factor (FOS) is a valid index to evaluate the stability of geotechnical structure which is widely used in geotechnical engineering. Presently, the safety factor used in geotechnical stability analysis is mostly calculated by the finite element method with shear strength reduction technique (SSRFEM) [5-9]. Based on this method, the safety factor and critical failure surface can be obtained by reducing the actual shear strength parameters until geotechnical material fails. So the accuracy of FOS derived from SSRFEM relies strongly on the determination of failure of geotechnical structure. However, the definition of failure for geotechnical structure is a disputed issue. Griffiths and Lane [10] chose the nonconvergence of algorithm as the indicator of failure for homogeneous slope. Snitbhan and Chen [11] regarded bulging or progressive loss of ground along the vertical cut as the failure of vertical slope. As there is divergence of definition for failure in the geotechnical engineering field, the different definition of failure would induce different analysis result, which confines the application of SSRFEM in geotechnical engineering.

Large numbers of theoretical researches and practical projects illustrate that the failure of shallow tunnel face can be divided into collapse and blow-out failure mechanisms. The collapse failure mechanism is used to describe the collapse of soil in front of the tunnel face, which is caused by the insufficient retaining pressure on the tunnel face. Contrarily, blow-out failure mechanism occurs when 
the retaining pressure is so great that soil is heaved in front of the tunnel face. Based on the failure mode and kinematically admissible velocity characteristic of the shallow tunnel face, Leca and Dormieux [12] proposed a three-dimensional failure mechanism composed of solid conical blocks. Due to the slide between the solid conical blocks and surrounding soil, the plastic flow occurs along the velocity discontinuity surface. Using the energy dissipation rate along the surface and the rate of work caused by external force, Leca and Dormieux [12] derived the upper bound solution of retaining pressure for tunnel face. As the mechanism proposed by Leca and Dormieux [12] is supported by centrifuge model tests and well reflects the mechanical characteristics of failure mode for shallow tunnel face, many scholars used this mechanism to analyze the stability of shallow tunnel face under various conditions [13-16].

These literatures mentioned above all used linear MohrCoulomb criterion. However, the stress-strain relation of soils and rocks is nonlinear. This viewpoint has been supported by experiments and some scholars used nonlinear failure criterion to study the stability of tunnel face and other geotechnical structures $[17,18]$. Based on the failure mechanism proposed by Leca and Dormieux [12], Huang and Yang [19] calculated the upper bound solution of retaining pressure on the tunnel face using the upper bound theorem in conjunction with nonlinear failure criterion. Senent et al. [20] studied the face stability of circular tunnels excavated in heavily fractured rock masses which are subjected to the nonlinear Hoek-Brown failure criterion. According to their study, the critical retaining pressures computed with limit analysis are very similar to those obtained with the numerical model, which proves their method is valid. Though their studies reflect the influence of nonlinearity on the critical retaining pressures, they failed to propose a method to evaluate the stability of tunnel face when the retaining pressure is known.

In this work, upper bound theorem combined with shear strength reduction technique is used to estimate the face stability of a tunnel excavated in shallow strata following the nonlinear failure criterion. On the basis of upper bound theorem, the rate of external work and the internal energy rate of dissipation for the failure mechanism are calculated. Based on the relationship between the rate of external work and the internal energy rate of dissipation, the convergence of iteration in the strength reduction calculation can be controlled, which avoids the selection of the definition of failure that occurs in the SSRFEM calculation process. To validate the new methodology, the FOS of tunnel face is compared with the result computed by limit equilibrium method. Furthermore, the influence of nonlinear parameter on the stability of tunnel face is investigated.

\section{Upper Bound Theorem with Shear Strength Reduction Technique}

Shear strength reduction technique was proposed by Bishop [22], whose core content is the reduction of soil shear strength parameters until the soil fails. To achieve this reduction, an important concept is introduced, the shear strength reduction factor $F_{s}$. When the actual shear strength parameters $c$ and $\phi$ are divided by the shear strength reduction factor, the soil strength parameters $c_{f}$ and $\phi_{f}$ used in upper bound analysis are obtained

$$
\begin{aligned}
c_{f} & =\frac{c}{F_{s}}, \\
\phi_{f} & =\arctan \left(\tan \frac{\phi}{F_{s}}\right) .
\end{aligned}
$$

While shear strength reduction factor $F_{s}$ increases incrementally, newly reduced soil strength parameters are obtained. The iterative process continues until failure occurs.

As mentioned above, the selection of a suitable definition of failure is a problem in SSRFEM. To overcome this difficulty, the upper bound theorem is used to control the convergence of iterative operation in the strength reduction technique. The upper bound theorem states that when the velocity boundary condition is satisfied, the load derived by equating the rate of external work to the rate of the energy dissipation in any kinematically admissible velocity field is no less than the actual collapse load. Therefore, if the reduced soil strength parameters are introduced in the energy dissipation calculation, the shear strength reduction factor can be obtained on the basis of the relationship between the rate of external work and the rate of the energy dissipation.

\section{Upper Bound Solution of FOS for Shallow Tunnel Face}

In this work, the failure mechanisms proposed by Leca and Dormieux [12] are used to calculate the rate of external work and the rate of the energy dissipation in the framework of the upper bound theorem of limit analysis. The failure mechanism of Leca and Dormieux [12] is composed of collapse and blow-out failure mechanisms, which is shown in Figure 1. For instance, we use failure mechanism III to illustrate the computational process of the upper bound solution of FOS. As Leca and Dormieux [12] have computed the rate of external work $P_{e}$ for mechanism III, the expression of $P_{e}$ can be written as

$$
\begin{aligned}
P_{e} & =\frac{\pi D^{2}}{4}\left[-\frac{R_{B} R_{C}^{2}}{\cos \phi} \sigma_{s}\right. \\
& \left.-\frac{1}{3} \sin \alpha \frac{\left(R_{B} R_{C} / \sin \alpha\right)^{3}-\left(R_{A} / \cos \alpha\right)^{3}}{\sin 2 \phi \cos \phi} \gamma D\right] V,
\end{aligned}
$$

where $D$ is the tunnel diameter, $\gamma$ is the unit weight of the soil, $\phi$ is the friction angle of the soil, $\sigma_{s}$ is surcharge loading, $V$ is the velocity of conical block, $\alpha$ is the angle between symmetry axis of conical block and centre line of the tunnel, and the parameters $R_{A}, R_{B}, R_{C}$ are expressed as

$$
\begin{aligned}
& R_{A}=\cos \alpha \sqrt{\cos (\alpha+\phi) \cos (\alpha-\phi)}, \\
& R_{B}=\sin \alpha \sqrt{\sin (\alpha+\phi) \sin (\alpha-\phi),} \\
& R_{C}=\frac{\sin 2 \alpha+(2 C / D+1) \sin 2 \phi}{\cos 2 \phi-\cos 2 \alpha},
\end{aligned}
$$



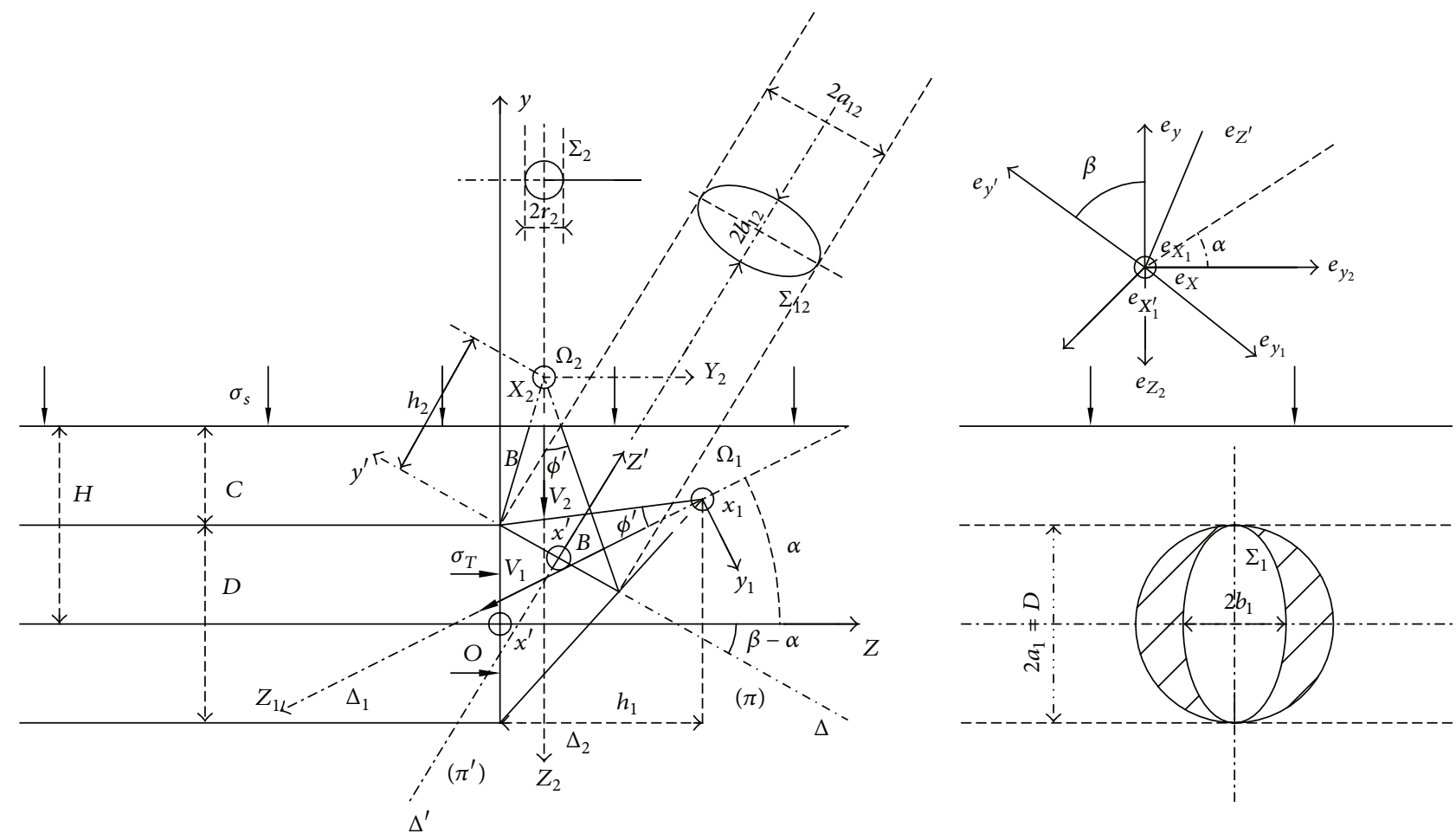

(a) Failure mechanism II
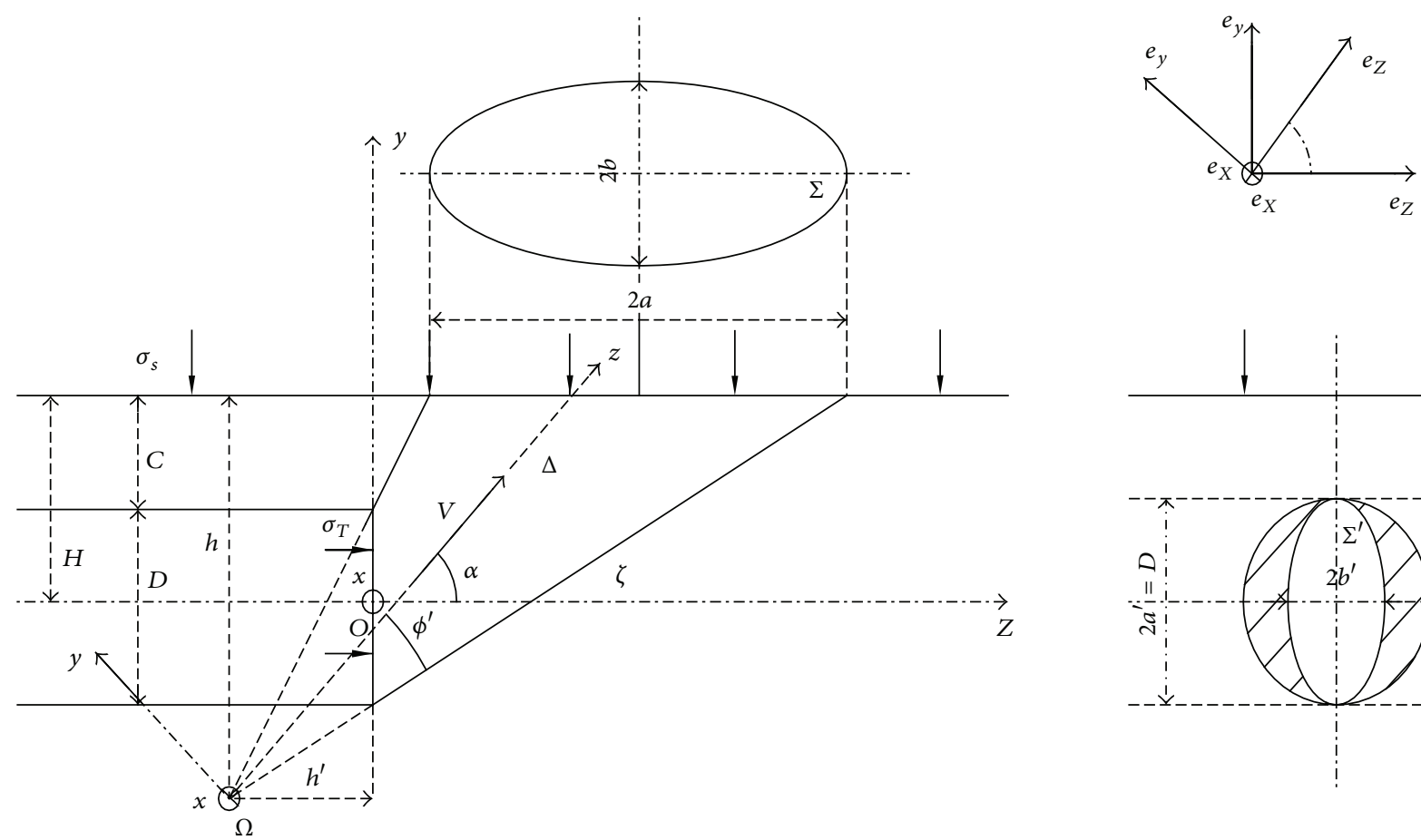

(b) Failure mechanism III

FIGURE 1: Failure mechanism of tunnel face proposed by Leca and Dormieux [12]. 


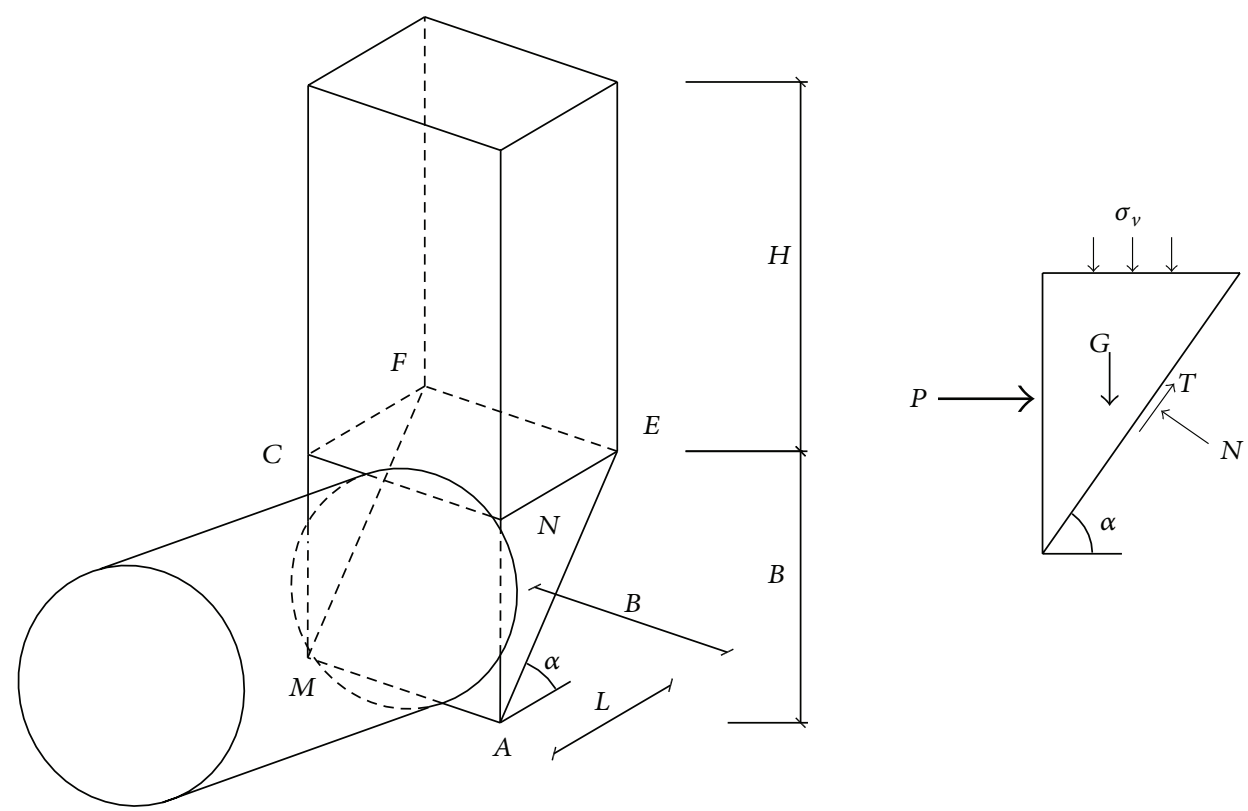

FIgURE 2: Wedge stability model of tunnel face proposed by Anagnostou and Kovári [21].

where $C$ is the tunnel depth. Moreover, the rate of the energy dissipation produced in kinematically admissible velocity field is

$$
P_{V}=\frac{\pi D^{2}}{4}\left[R_{B} R_{C}^{2}-R_{A}\right] \frac{c V}{\sin \phi}
$$

where $c$ is the cohesion of soil. Based on the upper bound theorem, the expression of retaining pressure $\sigma_{T}$ is obtained by equaling the rate of external work to the rate of the energy dissipation

$$
\sigma_{T}=\frac{P_{V}-P_{e}}{\left(\pi D^{2} R_{A} / 4 \cos \phi\right) V} .
$$

To calculate the upper bound solution of FOS, the initial cohesion $c$ and friction angle $\phi$ of soil are substituted into (1) to obtain the reduced strength parameters $c_{f}$ and $\phi_{f}$. Then, the reduced strength parameters $c_{f}$ and $\phi_{f}$ are substituted into (2) and (4) to derive the upper bound solution of retaining pressure $\sigma_{T}$. Finally, by equaling the practical retaining pressure to the retaining pressure $\sigma_{T}$ expressed in (5), the objective function of safety factor $f\left(\alpha, F_{s}\right)$ which includes an angle variable is obtained. However, the objective function $f\left(\alpha, F_{s}\right)$ is just an expression of numerous upper bound solutions. According to the upper bound theorem, the minimum value of objective function $f\left(\alpha, F_{s}\right)$ is the real upper bound solution of FOS. Therefore, a sequential quadratic programming is employed to search the minimum value of objective function $f\left(\alpha, F_{s}\right)$. As some compatibility relations of velocity should be satisfied in the kinematically admissible velocity field, the optimization calculation is achieved when corresponding constraint conditions are satisfied. Therefore, the expression of mathematical planning for the problem can be written as

$$
\begin{array}{ll}
\min & F_{s}=F_{s}\left(\alpha, F_{s}\right), \\
\text { s.t. } & \left\{P_{\gamma}+P_{T}=P_{V}, \phi<\alpha<\frac{\pi}{2}-\phi\right\},
\end{array}
$$

where $P_{T}$ is the power of practical retaining pressure.

\section{Comparison with the Results Computed by Limit Equilibrium Method}

To evaluate the validity of the method proposed in this work, the FOS of tunnel face is calculated by limit equilibrium method and the upper bound theorem with shear strength reduction technique. Numerical results for these two methods with different parameters are presented and compared with each other.

Based on the silo theory, a three-dimensional failure mode of the tunnel face composed of wedges, as shown in Figure 2, is proposed by Anagnostou and Kovári [21] in the framework of limit equilibrium method. According to Bishop [22], the FOS for slope can be defined as the ratio of the available shear strength of the soil to that required to maintain equilibrium. Therefore, the FOS of tunnel face derived from the wedge model presented in Figure 2 is expressed as follows:

$$
\mathrm{FOS}=\frac{F_{r}}{F_{i}},
$$

where $F_{r}$ is the shearing resistance force and $F_{i}$ is the shearing force acting on the wedge base. The detailed calculating procedure of $F_{r}$ and $F_{i}$ can be seen in the appendix. 


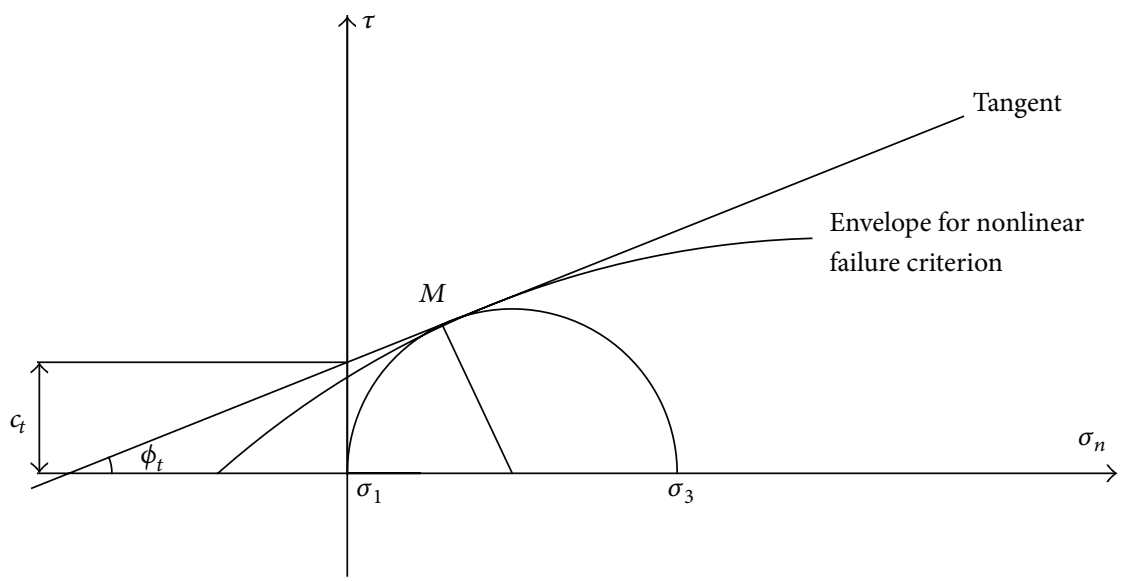

FIGURE 3: Generalized tangential technique for a nonlinear failure criterion.

TABLE 1: Comparison of FOS for tunnel face.

\begin{tabular}{lcccccc}
\hline \multirow{2}{*}{ Number $C / D$} & $\gamma\left(\mathrm{kN} / \mathrm{m}^{3}\right)$ & $\phi\left(^{\circ}\right)$ & $\sigma_{T}(\mathrm{~Pa})$ & \multicolumn{2}{c}{ FOS } \\
& & & & & LEM & LAM \\
\hline 1 & 0.4 & 20 & 20 & 24960 & 1.0442354 & 1.0085697 \\
2 & 0.4 & 20 & 25 & 18120 & 1.0395553 & 1.0189546 \\
3 & 0.4 & 20 & 30 & 12960 & 1.0307114 & 1.0094596 \\
4 & 0.4 & 20 & 35 & 10560 & 1.031479 & 1.0074599 \\
5 & 0.4 & 20 & 40 & 7920 & 1.0314455 & 1.0098653 \\
6 & 0.4 & 20 & 45 & 6000 & 1.0327247 & 1.0112345 \\
\hline
\end{tabular}

Dawson et al. [23] pointed out that if the actual height of slope is equal to the critical height computed by the upper bound theorem, the FOS of the slope is exactly 1.0. Similarly, if the actual retaining pressure applied on the tunnel face is equal to the upper solution of retaining pressure, the FOS of tunnel face calculated by this method should also be 1.0.

Table 1 presents FOS of tunnel face calculated by LEM and LAM for $C / D=0.4$ and $\gamma=20 \mathrm{kN} / \mathrm{m}^{3}$, with the $\phi$ varying from $20^{\circ}$ to $45^{\circ}$. The retaining pressures $\sigma_{T}$ presented in Table 1 are the upper solutions computed by Leca and Dormieux [12]. It is found from Table 1 that the FOS of tunnel face computed by the method proposed in this paper is almost equal to those using the limit equilibrium method. Therefore, the good agreement between these two methods shows that the method proposed in this paper is an effective method for calculating the FOS of shallow tunnel face.

\section{Nonlinear Failure Criterion and Generalized Tangential Technique}

Zhang and Chen [24] adopted a nonlinear expression to describe the relationship between the normal and shear stress when a plastic flow of geotechnical materials occurs, which is expressed as

$$
\tau=c_{0}\left(1+\frac{\sigma_{n}}{\sigma_{t}}\right)^{1 / m},
$$

where $\sigma_{n}$ and $\tau$ are the normal and shear stresses on the failure surface, respectively, and $c_{0}, \sigma_{t}$, and $m$ are material parameters determined by geotechnical test. As the strength envelope of this nonlinear failure criterion is curve, the strength parameter of geotechnical materials cannot be determined like linear Mohr-Coulomb failure criterion. To overcome this difficulty, Yang and Yin [25] proposed a generalized tangential technique which uses a tangential line on the nonlinear failure criterion at point $M$ to determine the strength parameter. The tangential line on the curve at the location of tangency point $M$ as shown in Figure 3 can be written as

$$
\tau=c_{t}+\sigma_{n} \tan \phi_{t},
$$

where $\phi_{t}$ is a tangential frictional angle and $c_{t}$ is the intercept of the straight line on the $\tau$-axis. $c_{t}$ and $\phi_{t}$ can be obtained by the following two expressions:

$$
\begin{aligned}
c_{t}= & \frac{m-1}{m} \cdot c_{0}\left(\frac{m \cdot \sigma_{t} \cdot \tan \phi_{t}}{c_{0}}\right)^{1 /(1-m)}+\sigma_{t} \\
& \cdot \tan \phi_{t}, \\
\tan \phi_{t}= & \frac{c_{0}}{m \sigma_{t}}\left(1+\frac{\sigma_{n}}{\sigma_{t}}\right)^{(1-m) / m} .
\end{aligned}
$$

Since the tangential line in Figure 3 is random, $\phi_{t}$ is regarded as a variable to calculate the rate of external work and energy dissipation. Using sequential quadratic programming, the upper bound solution of objective function and corresponding value of $\phi_{t}$ are obtained. Obviously, the tangential line is determined by optimization calculation, which indicates that nonlinear failure criterion represented by the tangential line will provide the optimum upper bound of actual load for the geotechnical material.

\section{Upper Bound Solution of FOS with Nonlinear Failure Criterion}

To study the effect of the nonlinear parameter on the FOS of tunnel face, upper bound solutions of FOS are calculated by the method proposed in this paper with different 


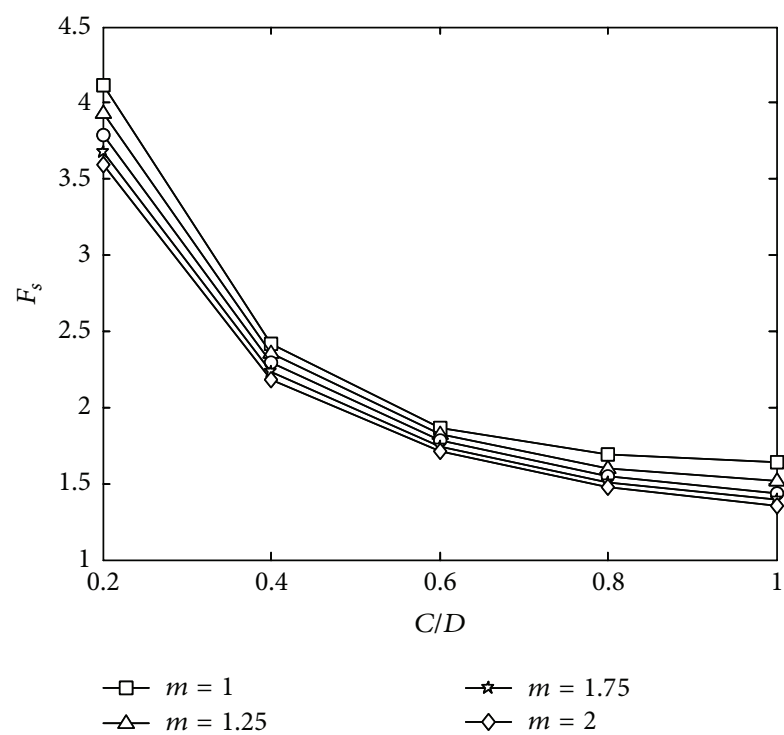

(a)

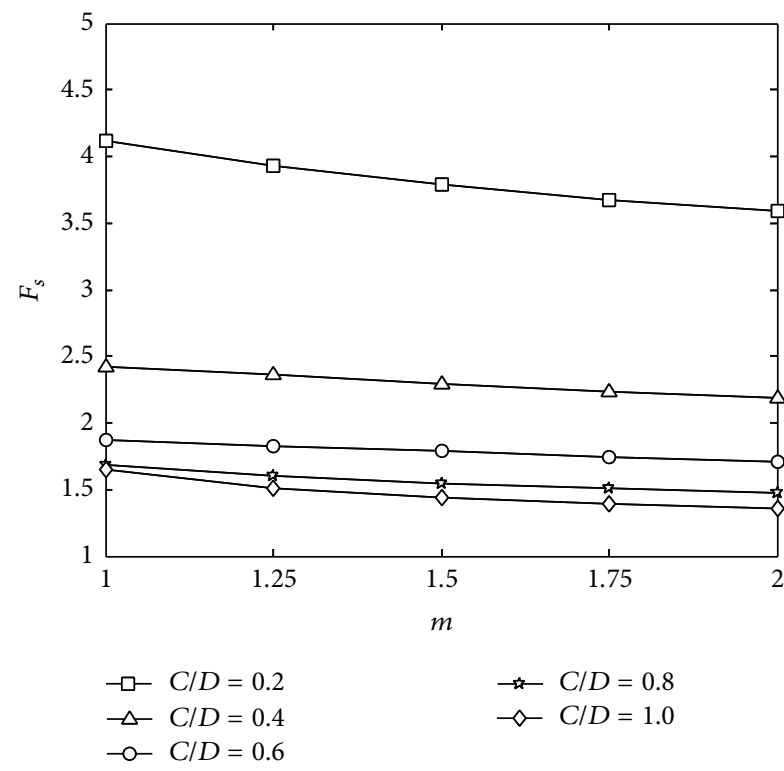

(b)

FIGURE 4: Effect of $m$ and $C / D$ on the FOS for collapse failure mechanism $\left(\sigma_{T}=5 \mathrm{kPa}, \gamma=20 \mathrm{kN} / \mathrm{m}^{3}, c_{0}=10 \mathrm{kPa}, \sigma_{t}=24.73 \mathrm{kPa}, C / D=0.2 \sim 1\right.$, $m=1.0 \sim 2.0)$.

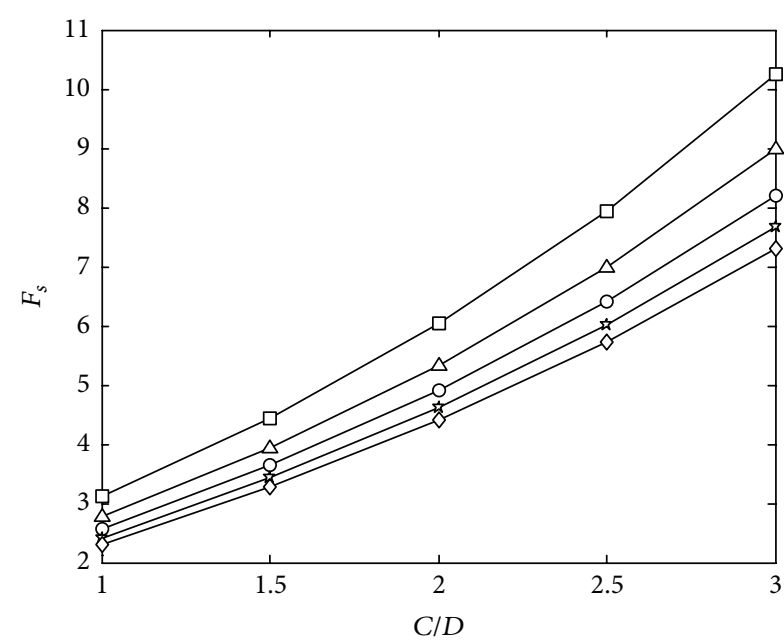

$\square-m=1$
$\triangle m=1.25$
$\multimap-m=1.5$

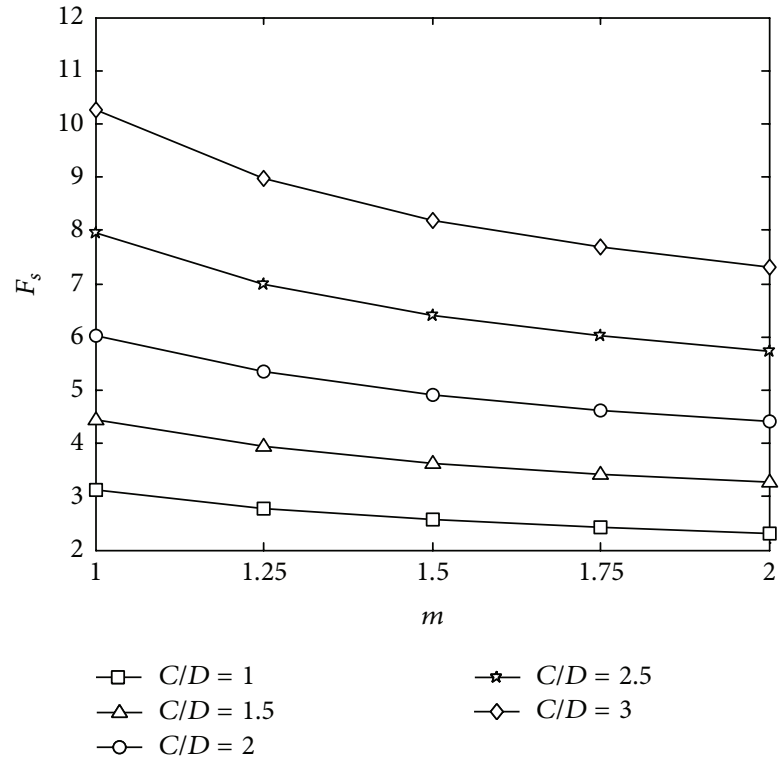

(b)

FIGURE 5: Effect of $m$ and $C / D$ on the FOS for blow-out failure mechanism $\left(\sigma_{T}=800 \mathrm{kPa}, \gamma=20 \mathrm{kN} / \mathrm{m}^{3}, c_{0}=90 \mathrm{kPa}, \sigma_{t}=247.3 \mathrm{kPa}, C / D=\right.$ $1 \sim 3, m=1.0 \sim 2.0$ ).

parameters. As nonlinear coefficient $m$ which controls the shape of strength envelope for nonlinear failure criterion has significant influence on the other parameters, this paper focuses on the effect of $m$ on FOS. Using the collapse failure mechanism, the upper bound solutions of FOS with different nonlinear coefficient $m$ are plotted in Figure 4 with $\sigma_{T}=5 \mathrm{kPa}$, $\gamma=20 \mathrm{kN} / \mathrm{m}^{3}, c_{0}=10 \mathrm{kPa}, \sigma_{t}=24.73 \mathrm{kPa}$, and depth ratio $C / D$ $=0.2 \sim 1$. It can be found from Figure 4 that the FOS decreases with the increase of $m$ and $C / D$ for collapse failure mechanism. Similarly, Figure 5 shows the change law of FOS for varying $m$ and $C / D$ with parameters corresponding to $\sigma_{T}=$ $800 \mathrm{kPa}, \gamma=20 \mathrm{kN} / \mathrm{m}^{3}, c_{0}=90 \mathrm{kPa}$, and $\sigma_{t}=247.3 \mathrm{kPa}$ on 
the basis of blow-out failure mechanism. Figure 5 shows that the values of FOS tend to increase directly with the depth ratio $C / D$ and inversely with $m$.

It can be seen that the change trend of depth ratio $C / D$ on the FOS for collapse failure mechanism is just opposite to that of the blow-out failure mechanism. This phenomenon is caused by the different velocity of solid conical blocks in kinematically admissible velocity field for these two failure mechanisms. In the kinematically admissible velocity field of collapse failure mechanism, the velocity component of solid conical block in front of the tunnel face moves in the opposite direction of the tunnel excavation. On the contrary, in kinematically admissible velocity field of blow-out failure mechanism, induced by the huge retaining pressure on tunnel face, the velocity component of solid conical block in front of the tunnel face moves in the direction of the tunnel excavation. As the velocities of solid conical block in these two failure mechanisms are opposite, the effects of power of the soil weight on the energy dissipation calculation are also opposite. Therefore, when collapse failure occurs on the tunnel face, low value of depth ratio $C / D$ will contribute to the tunnel stability. However, when blow-out failure occurs on the tunnel face, high value of depth ratio $C / D$ will contribute to the tunnel stability. On the other hand, with the increase of nonlinear coefficient $m$ the values of $c_{t}$ and $\phi_{t}$ obtained by generalized tangential technique both decrease. As $c_{t}$ and $\phi_{t}$ are used to calculate the energy dissipation and the energy dissipation is independent of velocity of solid conical blocks, the change laws of nonlinear coefficient $m$ on FOS for these two failure mechanisms are the same.

\section{Conclusion}

The upper bound theorem combined with shear strength reduction technique is adopted to calculate the FOS of shallow tunnel face in the framework of nonlinear failure criterion. Upper bound solutions of FOS are derived from collapse and blow-out failure mechanisms proposed by Leca and Dormieux [12]. Using generalized tangential technique, the nonlinear failure criterion is introduced in the energy dissipation calculation.

The upper bound solutions of FOS are compared with the results calculated by limit equilibrium method. The solutions of FOS derived in this paper are almost equal to those calculated by limit equilibrium method, which proves that the method proposed in this paper is effective.

Based on the motion features of solid conical block in kinematically admissible velocity field for these two failure mechanisms, the reason for different effect of depth ratio on FOS is explained. By parameter study, it is found that the parameters $m$ and $C / D$ have large influence on the FOS of shallow tunnel face.

\section{Appendix}

According to Qiao et al. [26], the detailed calculating procedure of $F_{r}$ and $F_{i}$ can be illustrated as follows. On the basis of
Terzaghi relation soil pressure theory, the three-dimensional relation soil pressure is

$$
\begin{aligned}
\sigma_{v}= & \frac{\gamma-\lambda \cdot c}{\lambda \cdot k_{0} \cdot \tan \phi} \cdot\left[1-e^{-\lambda \cdot k_{0} \cdot Z \cdot \tan \phi}\right]+P_{0} \\
& \cdot e^{-\lambda \cdot k_{0} \cdot Z \cdot \tan \phi},
\end{aligned}
$$

where $k_{0}$ is lateral pressure coefficient, $\gamma$ is the unit weight of the soil, $c$ is the cohesion of soil, $\phi$ is the friction angle of the soil, $Z$ is the distance between tunnel roof and ground surface, $P_{0}$ is surcharge pressure, and $\lambda$ can be calculated by the following expression:

$$
\lambda=\frac{2(\tan \alpha-1 /(\tan \beta+1 / \sin \beta))}{B(1-1 / \tan \alpha)},
$$

where $\alpha, \beta$, and $B$ are parameters which can be seen in Figure 2. The soil pressure is

$$
P_{v}=\sigma_{v} \cdot A_{\mathrm{CNEF}}
$$

where $A_{C N E F}$ is the area of CNEF. The weight of the wedge is

$$
G=\frac{D^{2}}{2} \cdot \cot \alpha \cdot B \cdot \gamma
$$

where $D$ is tunnel diameter. Using static equilibrium equation, the pressure $N$ is obtained

$$
N=P \sin \alpha+\left(G+P_{v}\right) \cos \alpha,
$$

where $P$ is retaining pressure. Based on the Mohr-Coulomb failure criterion, the friction resistance $T$ of slip surface $A M E F$ in the wedge is derived

$$
T=c \cdot A_{A M E F}+N \cdot \tan \phi,
$$

where $A_{A M E F}$ is the area of slip surface $A M E F$ in the wedge. Thus, the shearing resistance force $F_{r}$ and the shearing force $F_{i}$ can be written as

$$
\begin{aligned}
& F_{r}=T+P \cdot \cos \alpha, \\
& F_{i}=\left(G+P_{v}\right) \cdot \sin \alpha .
\end{aligned}
$$

\section{Competing Interests}

The authors declare that the mentioned received funding in the Acknowledgments did not lead to any competing interests regarding the publication of this paper.

\section{Acknowledgments}

The preparation of this paper received financial support from the National Natural Science Foundation of China (nos. 51308072 and 51278071), Educational Commission of Hunan Province of China (no. 15C0052), and Innovation Research Project of Priority Key Disciplines at Changsha University of Science and Technology (no. 15ZDXK13). The financial supports are greatly appreciated. 


\section{References}

[1] M. Ahmed and M. Iskander, "Evaluation of tunnel face stability by transparent soil models," Tunnelling and Underground Space Technology, vol. 27, no. 1, pp. 101-110, 2012.

[2] R. P. Chen, J. Li, L. G. Kong, and L. J. Tang, "Experimental study on face instability of shield tunnel in sand," Tunnelling and Underground Space Technology, vol. 33, no. 1, pp. 12-21, 2013.

[3] S. H. Kim and F. Tonon, "Face stability and required support pressure for TBM driven tunnels with ideal face membraneDrained case," Tunnelling and Underground Space Technology, vol. 25, no. 5, pp. 526-542, 2010.

[4] P. Oreste, "Face stabilization of deep tunnels using longitudinal fibreglass dowels," International Journal of Rock Mechanics and Mining Sciences, vol. 58, pp. 127-140, 2013.

[5] H. Zheng, G. H. Sun, and D. F. Liu, "A practical procedure for searching critical slip surfaces of slopes based on the strength reduction technique," Computers and Geotechnics, vol. 36, no. 1-2, pp. 1-5, 2009.

[6] T. Wang, H. G. Wu, Y. Li et al., "Stability analysis of the slope around flood discharge tunnel under inner water exosmosis at Yangqu hydropower station," Computers and Geotechnics, vol. 51, pp. 1-11, 2013.

[7] W. B. Wei and Y. M. Cheng, "Strength reduction analysis for slope reinforced with one row of piles," Computers and Geotechnics, vol. 36, no. 7, pp. 1176-1185, 2009.

[8] M. S. Huang and C. Q. Jia, "Strength reduction FEM in stability analysis of soil slopes subjected to transient unsaturated seepage," Computers and Geotechnics, vol. 36, no. 1-2, pp. 93-101, 2009.

[9] S. M. Marandi, M. Anvar, and M. Bahrami, "Uncertainty analysis of safety factor of embankment built on stone column improved soft soil using fuzzy logic $\alpha$-cut technique," Computers and Geotechnics, vol. 75, pp. 135-144, 2016.

[10] D. V. Griffiths and P. A. Lane, "Slope stability analysis by finite elements," Géotechnique, vol. 49, no. 3, pp. 387-403, 1999.

[11] N. Snitbhan and W.-F. Chen, "Elastic-plastic large deformation analysis of soil slopes," Computers and Structures, vol. 9, no. 6, pp. 567-577, 1978.

[12] E. Leca and L. Dormieux, "Upper and lower bound solutions for the face stability of shallow circular tunnels in frictional material," Geotechnique, vol. 40, no. 4, pp. 581-606, 1990.

[13] I. M. Lee, J. S. Lee, and S. W. Nam, "Effect of seepage force on tunnel face stability reinforced with multi-step pipe grouting," Tunnelling and Underground Space Technology, vol. 19, no. 6, pp. 551-565, 2004.

[14] Y. Li, F. Emeriault, R. Kastner, and Z. X. Zhang, "Stability analysis of large slurry shield-driven tunnel in soft clay," Tunnelling and Underground Space Technology, vol. 24, no. 4, pp. 472-481, 2009.

[15] I. M. Lee and S. W. Nam, "The study of seepage forces acting on the tunnel lining and tunnel face in shallow tunnels," Tunnelling and Underground Space Technology, vol. 16, no. 1, pp. 31-40, 2001.

[16] H. T. Wang and J. Q. Jia, "Face stability analysis of tunnel with pipe roof reinforcement based on limit analysis," Electronic Journal of Geotechnical Engineering, vol. 14, pp. 1-15, 2009.

[17] X. L. Yang and Z. X. Long, "Seismic and static 3D stability of two-stage rock slope based on Hoek-Brown failure criterion," Canadian Geotechnical Journal, vol. 53, no. 3, pp. 551-558, 2016.
[18] X. L. Yang, J. S. Xu, Y. X. Li et al., "Collapse mechanism of tunnel roof considering joined influences of nonlinearity and non-associated flow rule," Geomechanics and Engineering, vol. 10, no. 1, pp. 21-35, 2016.

[19] F. Huang and X. L. Yang, "Upper bound solutions for the face stability of shallow circular tunnels subjected to nonlinear failure criterion," in Proceedings of the GeoShangai International Conference, Deep and Underground Excavations, pp. 251-256, Shangai, China, 2010.

[20] S. Senent, G. Mollon, and R. Jimenez, “Tunnel face stability in heavily fractured rock masses that follow the Hoek-Brown failure criterion," International Journal of Rock Mechanics and Mining Sciences, vol. 60, pp. 440-451, 2013.

[21] G. Anagnostou and K. Kovári, "Face stability conditions with Earth-Pressure-Balanced shields," Tunnelling and Underground Space Technology, vol. 11, no. 2, pp. 165-173, 1996.

[22] A. W. Bishop, "The use of the slip circle in the stability analysis of earth slopes," Géotechnique, vol. 5, no. 1, pp. 7-17, 1954.

[23] E. M. Dawson, W. H. Roth, and A. Drescher, "Slope stability analysis by strength reduction," Geotechnique, vol. 49, no. 6, pp. 835-840, 1999.

[24] X. J. Zhang and W. F. Chen, "Stability analysis of slopes with general nonlinear failure criterion," International Journal for Numerical and Analytical Methods in Geomechanics, vol. 11, no. 1, pp. 33-50, 1987.

[25] X. L. Yang and J. H. Yin, "Slope stability analysis with nonlinear failure criterion," Journal of Engineering Mechanics, vol. 130, no. 3, pp. 267-273, 2004.

[26] J. L. Qiao, Y. T. Zhang, J. Gao et al., "Application of strength reduction method to stability analysis of shield tunnel face," Journal of Tianjin University, vol. 43, no. 1, pp. 14-20, 2010. 


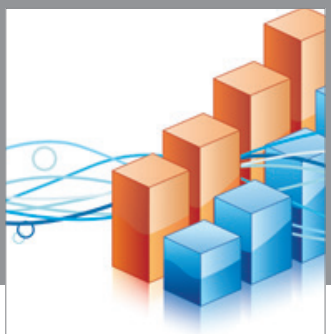

Advances in

Operations Research

vatem alat4

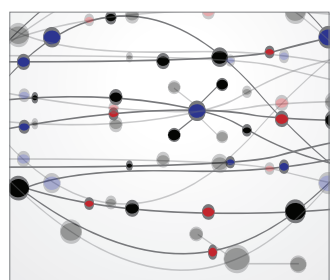

\section{The Scientific} World Journal
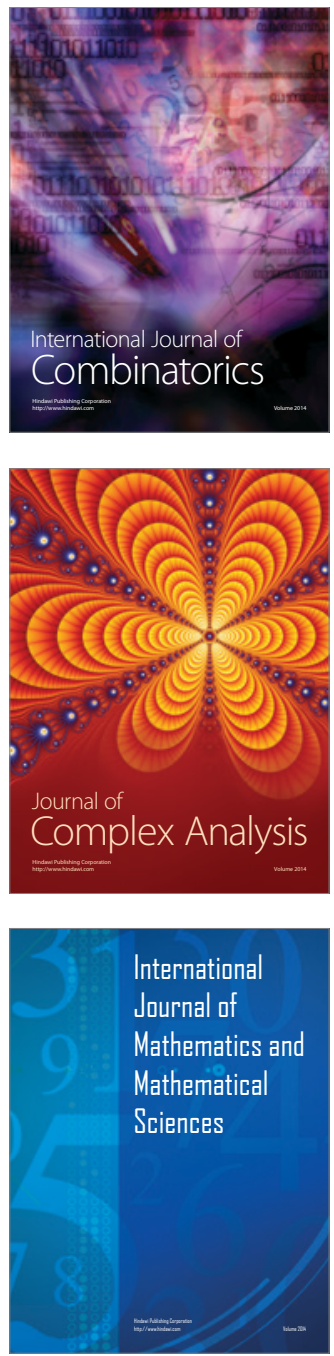
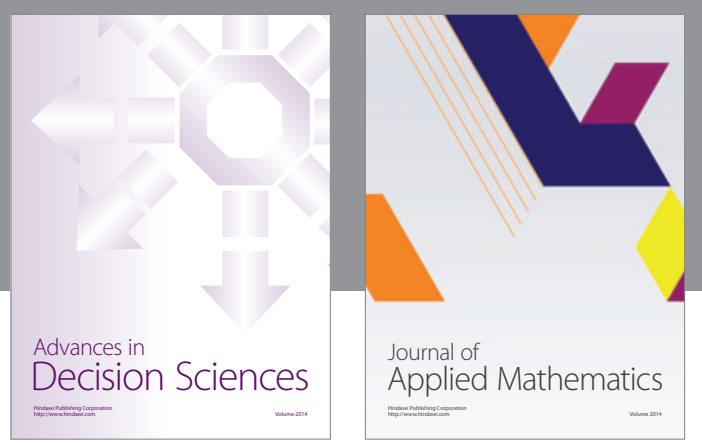

Algebra

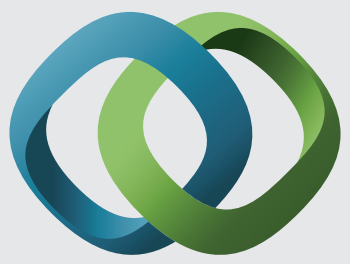

\section{Hindawi}

Submit your manuscripts at

http://www.hindawi.com
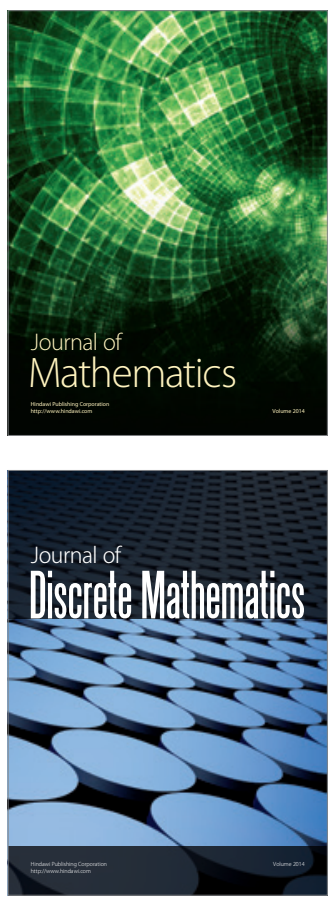

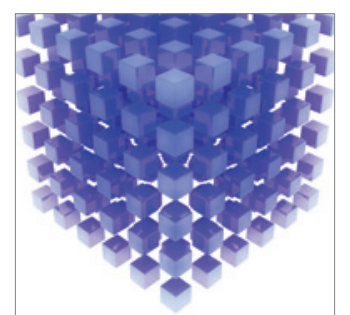

Mathematical Problems in Engineering
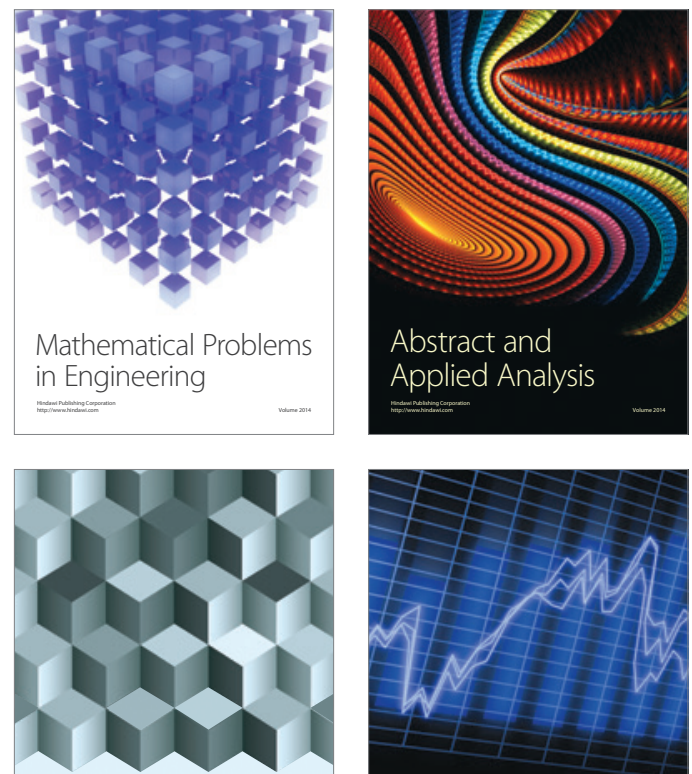

Journal of

Function Spaces

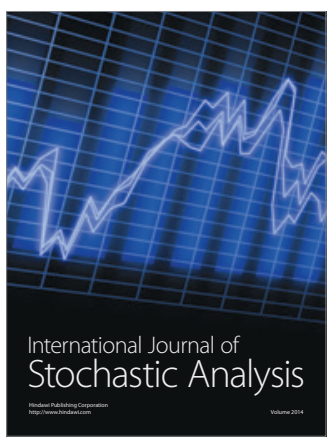

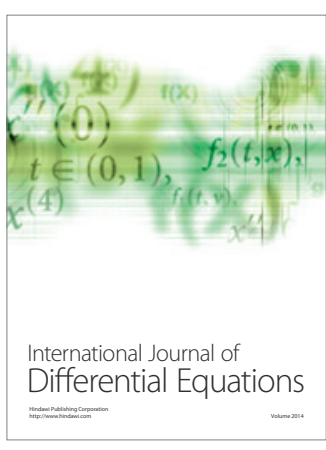
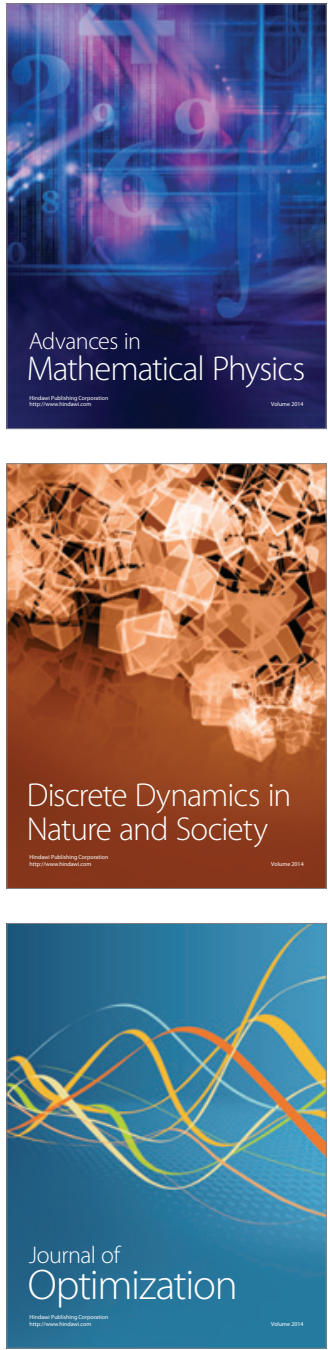